\title{
Two long-term slow slip events around Tokyo Bay found by GNSS observation during 1996-2011
}

Yoshiyuki Tanaka* ${ }^{*}$ (1) and Suguru Yabe ${ }^{2}$

\begin{abstract}
Slow slip events (SSEs) with durations ranging from days to more than a decade have been observed in plate subduction zones around the world. In the Kanto district in Japan, several SSEs have been identified based on geodetic observations. However, none of these events have had durations largely exceeding a year. In this study, we show that long-term SSEs with durations longer than 3 years occurred before the year 2000 and after 2007 on the upper interface of the Philippine Sea Plate at depths of 30-40 km. The fault model determined by inversion of global navigation satellite system data is located northeast of Tokyo Bay, where a seismic gap and low seismic wave velocities were detected by seismological observations. Moreover, the acceleration periods of the fault slip corresponded well with increases in the background seismicity for shallower earthquakes. The slip history was also temporally correlated with the long-term shear stress changes governed mainly by non-tidal variations in the ocean bottom pressure. However, the predicted slip from the long-term stress change was too small to reproduce the observed slow slips. To prove the causal relationship between the SSEs and the external stress change, more advanced modeling is necessary to confirm whether such a small slip can trigger an SSE.
\end{abstract}

Keywords: Slow slip events, Slow earthquakes, GNSS, Seismicity, Crustal deformation, Earthquake triggering, Ocean bottom pressure

\section{Background}

Geodetic and seismological observations have detected slow earthquakes in the circum-Pacific subduction zones since the late 1990s (Obara and Kato 2016). Slow earthquakes have different characteristic space-time scales, and a scaling law holds between their moment magnitudes $\left(M_{\mathrm{w}}\right)$ and durations (Ide et al. 2007). Among the slow earthquakes, long-term slow slip events (SSEs) occur along plate boundaries at depths of $30-40 \mathrm{~km}$, immediately beneath the source areas of megathrust earthquakes. Long-term SSEs have the largest $M_{\mathrm{w}}$ and longest durations, resulting in gradual fault slip without the emission of seismic waves. The durations of SSEs

\footnotetext{
*Correspondence: y-tanaka@eri.u-tokyo.ac.jp

1 Earthquake Research Institute, The University of Tokyo, Yayoi 1-1-1, Bunkyo-ku, Tokyo 113-0032, Japan

Full list of author information is available at the end of the article
}

range from a few days to more than several years (e.g., Nishimura 2014).

In the southern Kanto district in Japan, some slow earthquakes have been reported (Fig. 1a). In this area, the Philippine Sea Plate (PHS) subducts beneath the continental, Okhotsk Plate (OK) along the Sagami Trough. Moreover, the Pacific Plate (PAC) subducts under the PHS. Figure $1 \mathrm{~b}$ shows the depth contours determined by Hirose et al. (2008) and Nakajima et al. (2009). The directions of subduction of the PAC and the PHS relative to the continental plate are $\sim \mathrm{N} 70^{\circ} \mathrm{W}$ and $\sim \mathrm{N} 20^{\circ} \mathrm{W}$, respectively (e.g., Nishimura et al. 2007). The seismotectonics and the structure in the Kanto region is studied in detail in Nakajima et al. (2009), Uchida et al. (2010) and Ito et al. (2017), for example. A short-term SSE with a duration of $\sim 1$ day occurred in 1989 in the deeper portion of the asperity associated with the 1923 Kanto Earthquake (Hirose et al. 2000) (Fig. 1b). SSEs with durations of 10-14 days have repeatedly occurred off the 


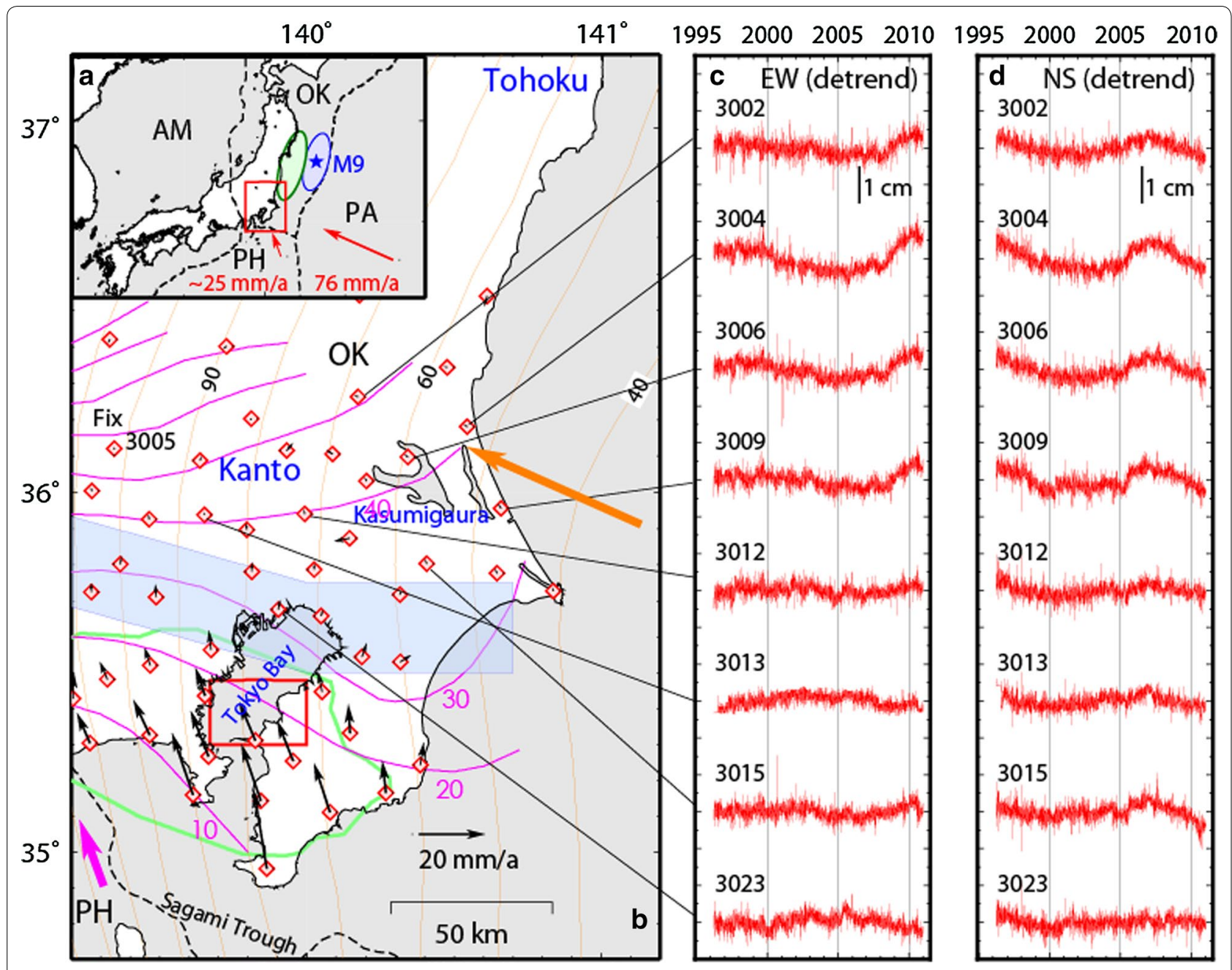

Fig. 1 The study area and an example of the GNSS data. a PA, OK, PH and AM denote the Pacific, Okhotsk, Philippine Sea and Amurian plates, respectively. The red arrows represent secular velocities of the oceanic plates relative to OK (Nishimura et al. 2007). In the area marked by the blue circle, large coseismic displacements were observed due to the M9 earthquake on March 11, 2011. The green circle denotes the area where a transient acceleration occurred during 1996-2011 (Mavrommatis et al. 2014). The red rectangle shows the study area, which is magnified below. b The diamonds and the black arrows denote the GNSS sites and linear background trends during 1996-2011, respectively. The orange/pink curves represent the contours of the plate boundary between OK and PA/PH (Hirose et al. 2008; Nakajima et al. 2009). The area surrounded by the green curve denotes the asperity of the 1923 Kanto earthquake. The red rectangle represents the area where a short-term SSE occurred (Hirose et al. 2000). c, d Examples of the detrended GNSS time-series data with the common errors and the episodic crustal deformations being removed (daily values)

Boso Peninsula (Ozawa 2014) at intervals of 2-7 years. In 2005 , aseismic vertical deformation with a duration of $\sim 1$ year occurred in the northeastern coastal area of Tokyo Bay (Kobayashi and Hirose 2016). Katsumata and Sakai (2013) explained changes in seismicity in the east Kanto area in 1997-2007 by assuming that a long-term SSE occurred during 2005-2007 on the upper interface of the PAC. The expected surface displacement, however, was smaller than the level detectable by the global navigation satellite system (GNSS).

Mavrommatis et al. (2014) analyzed GNSS data and reported that the plate subduction speed in eastern Japan accelerated during 1996-2011 at depths where large afterslip associated with the 2011 M9 Tohoku earthquake was observed (the area marked by the green circle in Fig. 1a). This deformation cannot be interpreted as a normal SSE because the slip velocity during an SSE is generally almost constant or decreases with time.

In this study, we investigated crustal deformation in the Kanto district, which is located at the southern edge of the region where the above acceleration was observed, using GNSS data from 1996 to 2011. In contrast to Mavrommatis et al. (2014), we put a reference station in an inland area and focused on the relative 
crustal deformation. This enables us to identify smaller spatial scale deformations than in their paper. We first extracted the background transient crustal behavior from the GNSS data by removing the effects of episodic events, such as earthquakes. Next, we inferred fault slip on the plate interfaces to explain the obtained transient motion. Finally, we compared the results with other geophysical data to evaluate the validity of the fault models.

\section{Methods}

\section{GNSS data analysis}

Figure $1 \mathrm{~b}$ shows the locations of the continuous GNSS observation stations operated by the Geospatial Information Authority of Japan (GSI) and employed in this study. To identify the background deformation, we processed the daily coordinates (F3 solution) as follows.

We removed artificial steps (e.g., those by antenna exchange) from the time-series data, using the offset file provided by the GSI. We then subtracted common errors due to scale change, translation and rotation of the whole GNSS network using the same method as described in supporting online material in Mavrommatis et al. (2014). We fixed the inland station 3005. The common errors affected only short-term deformations and were negligible when discussing long-term transient motions (Additional file 1: Fig. S1).

Next, we modeled and removed episodic deformations associated with three large earthquakes [Off the Kii Peninsula on September 5, 2004 (M7.4), the Mid Niigata Prefecture on October 23, 2004 (M6.8), and Off Ibaraki Prefecture on May 8, 2008 (M7.0)] by fitting a form of $y=a H(t)+b H(t)\left(1-e^{t / \tau}\right)$ against the time series, where $a$ and $b$ represent the coseismic offset and the postseismic change for each event, respectively, and $t=0$ denotes the time when the event initiated. $H(t)$ denotes the step function. We set $\tau$ as $1 / 3$ of the duration of the postseismic deformation that was obtained in independent studies (Sagiya et al. 2005; Suito and Ozawa 2008). This means that the sum of the co- and postseismic displacements is almost completely removed from the time series for $t>3 \tau$. The exponential approximation is sufficient for the current purpose because the durations of the postseismic deformations are only approximately two months (Additional file 1: Table S1). To extract long-term transients, we do not have to pay close attention to the accuracy of the tracking of the deformation during $0<t<3 \tau$.

The effects due to the 1996, 2002 and 2007 Boso SSEs (Ozawa 2014) and the 2000 eruption of Miyakejima volcano (Nishimura et al. 2001) were also removed in the same manner, except for setting $a=0$ in the above fitting function.

We confirmed that the effects of the other large earthquakes [e.g., the events that occurred off Fukushima
Prefecture on July 19, 2008 (M6.9), and on March 4, 2010 (M6.7), (Suito et al. 2011)] on these time series were negligible $(<1 \mathrm{~mm})$ using the fault models of Okada (1992).

The linear trends during 1996-2011 obtained from the corrected time series, estimated with an ordinary least-squares method, are superimposed in Fig. 1b. In south Kanto, the displacement rate vectors are directed $\mathrm{NNW}$ relative to the reference station, indicating that the continental Okhotsk plate and the PHS were strongly coupled with each other in the seismogenic zone. The displacement rates decreased toward the north and were 1-2 $\mathrm{mm}$ /year in regions north of Tokyo Bay. These features were consistent with the results of previous studies, and an average behavior could be interpreted using or slightly adjusting an already published kinematic model (e.g., Nishimura et al. 2007). Thus, we defined transient motion in this study as the displacement anomaly excluding the linear trend during 1996-2011 and inferred slip anomalies on the two plate boundaries that could explain this transient motion. In other words, we assumed that the average motion during 1996-2011 agreed with a steady-state motion that would be obtained from longerterm geodetic observations.

\section{Construction of the fault model}

We estimated uniform slip on two rectangular faults (Okada 1992), one at the upper interface of the PHS and another at the upper interface of the PAC. To discuss the longer-term transient motion, we input the displacement rates averaged over certain observation periods, rather than the daily displacements, into the inversion process. To decrease the number of fault parameters, we fixed the strike, dip and rake angles of the plate interface to $308^{\circ}, 20^{\circ}$ and $146^{\circ}$, respectively, for the PHS and $192^{\circ}, 23^{\circ}$ and $85^{\circ}$, respectively, for the PAC based on the kinematic model of Nishimura et al. (2007). We determined the slip velocity $U$, latitude $\lambda$, longitude $\varphi$, width $W$ and length $L$ of faults such that $V(U, \varphi, \lambda, W, L)=\sum\left[\left(O_{E}-C_{E}\right)^{2}+\left(O_{N}-C_{N}\right)^{2}\right] / \sigma^{2}$ was minimized using a grid search algorithm. Here, $O / C$ denotes the observed/calculated displacement rate at the $i$ th station, $\sigma$ is a constant and $E / N$ represents the $E-W / N-S$ component. Fault depths were dependent on the horizontal positions of the faults $(D=D(\varphi, \lambda))$ (i.e., fault locations are constrained to the plate boundary).

\section{Results}

\section{Transient motions}

Figure $2 \mathrm{a}-\mathrm{d}$ shows the spatial patterns of the sum of the co- and postseismic displacements caused by the episodic events discussed above $(a+b$ in the above fitting function). Figure $2 \mathrm{e}-\mathrm{f}$ displays the time-series displacement data at selected stations, obtained by removing 


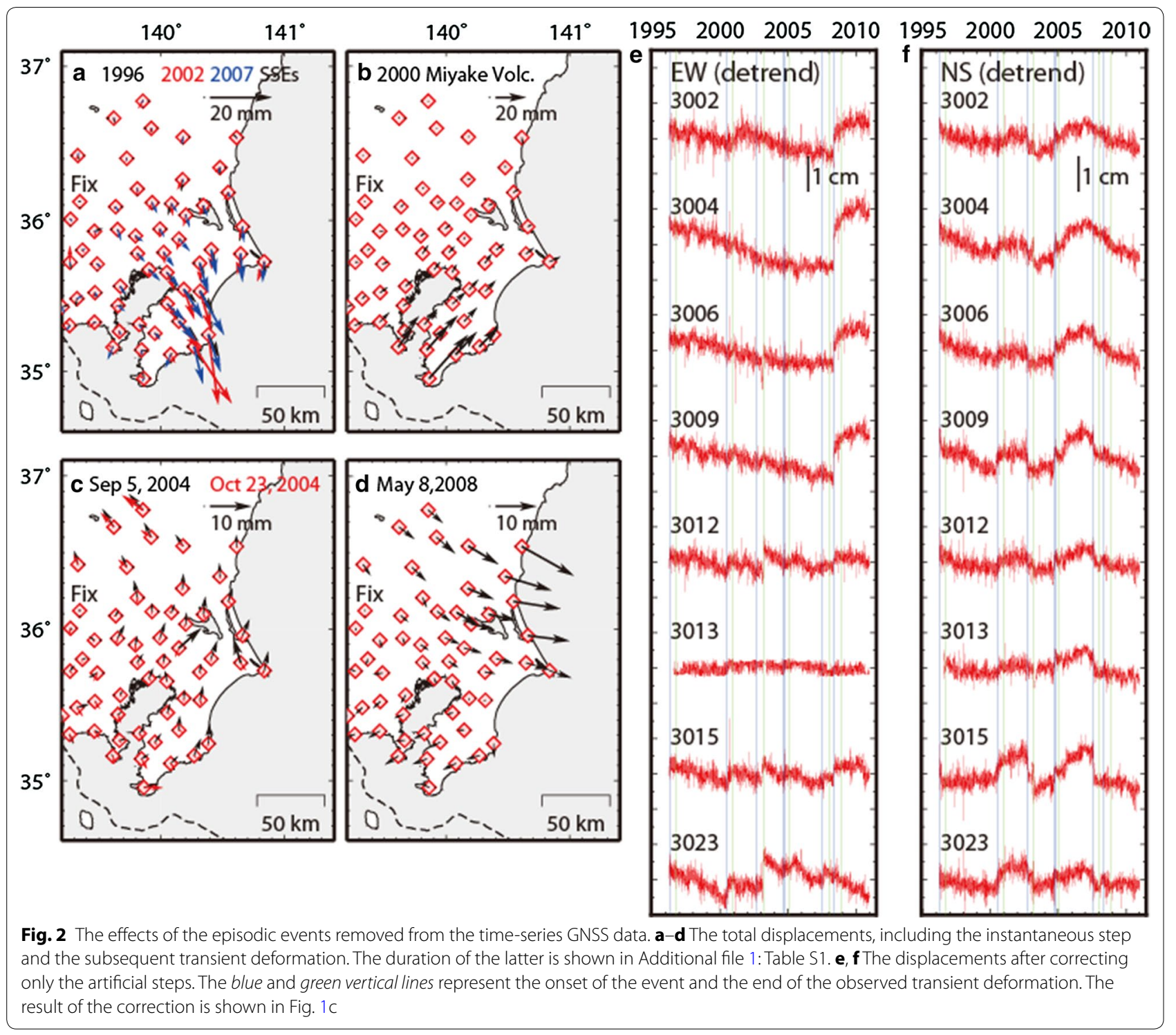

only the artificial steps and the linear trends. Figure 1c shows the transient motions at these stations, obtained by subtracting the effects of the episodic events and the common errors from the above time series and redetrending the result. Figure 1c shows that significant relative motions toward southeast with amplitudes of $\sim 1 \mathrm{~cm}$ occurred in 1996-2000 (Period I) and 20072011 (period II) at stations 3002-3009. These motions are not apparent ones caused by over/underestimating the effects of the episodic events (if any). At these stations, the steps due to the episodic effects shown in Fig. $2 \mathrm{a}-\mathrm{c}$ are at most a few $\mathrm{mm}$ and are therefore much smaller than the above amplitudes. Moreover, at the stations 3002-3015, the amount of the southward motion after the year 2007 is approximately the same as that of eastward motion. The combined coseismic and postseismic deformation due to the May 8 event (Fig. 2d) resulted in larger displacements in the easterly direction than in the southerly direction. Therefore, the enhanced southward motion after 2007 shown in Fig. 1c suggests that some phenomenon other than postseismic deformation is occurring.

The transient motions during periods I and II imply the presence of long-term SSEs. Their durations were 3-5 years (possibly longer for the earlier event), which is relatively long compared with the durations of long-term SSEs around the world. To the south, these southeastward motions became smaller, and the time-series plots exhibited more complicated behaviors due to superimposed short-period variations. 
Figure $3 \mathrm{a}-\mathrm{c}$ displays the average velocity fields during three periods, including periods I, II and between I and II. The rates during 2002-2006 were much smaller than during the other two periods, and the differences from the average motion during 19962011 were insignificant in most areas with the exception of south Boso. In contrast, in periods I and II, southeastward or southward displacement rates were common to the northeast of Tokyo Bay, including Ibaraki Prefecture and north Chiba. In period I, the displacement rates at stations around the fixed site were almost zero or oriented in random directions, with speeds of less than $\sim 1 \mathrm{~mm} /$ year. Therefore, we estimated that the amount of noise in the velocity field due to local environmental effects was approximately $1 \mathrm{~mm} /$ year, although the statistical uncertainties of the average velocities during the three periods, determined via the least-squares method, were negligible $(<0.1 \mathrm{~mm} /$ year $)$. In period II, the displacement rates were approximately twice as large as those in period I, and the directions were significantly deviated toward the east ( $>1 \mathrm{~mm} /$ year) (Fig. 3e).

\section{Slip rate anomalies at the plate boundaries}

The directions of the rates in period I were close to the opposite of those of the average motion of the PHS. Therefore, we first constructed a single-fault model on the upper boundary of the PHS to explain the velocity field in period I. The vectors in Fig. 3d show the velocity field of the best-fit model (Model S1) obtained by the grid search. The fault was distributed at depths of $30-40 \mathrm{~km}$ below the area to the northeast of Tokyo Bay. Table 1 shows the slip rate, the moment magnitude released over 4 years and the RMS of the velocity inversion. We see that the single-fault model with $M_{\mathrm{w}}=6.6$ can explain the observations within the supposed error $(\sigma<1 \mathrm{~mm} /$ year $)$. The changes in the variances for different fault parameters indicate that all the parameters were basically well determined (Additional file 1: Fig. S2).

Next, we estimated the slip rate on the upper interface of the PAC and that on the PHS, simultaneously (Model D1). Additional file 1: Fig. S3 shows the results. The slip on the PAC was distributed at depths of $30-40 \mathrm{~km}$, where the acceleration was dominant (Mavrommatis et al. 2014). The slip rate was $0.5 \mathrm{~mm} /$ year, which did not

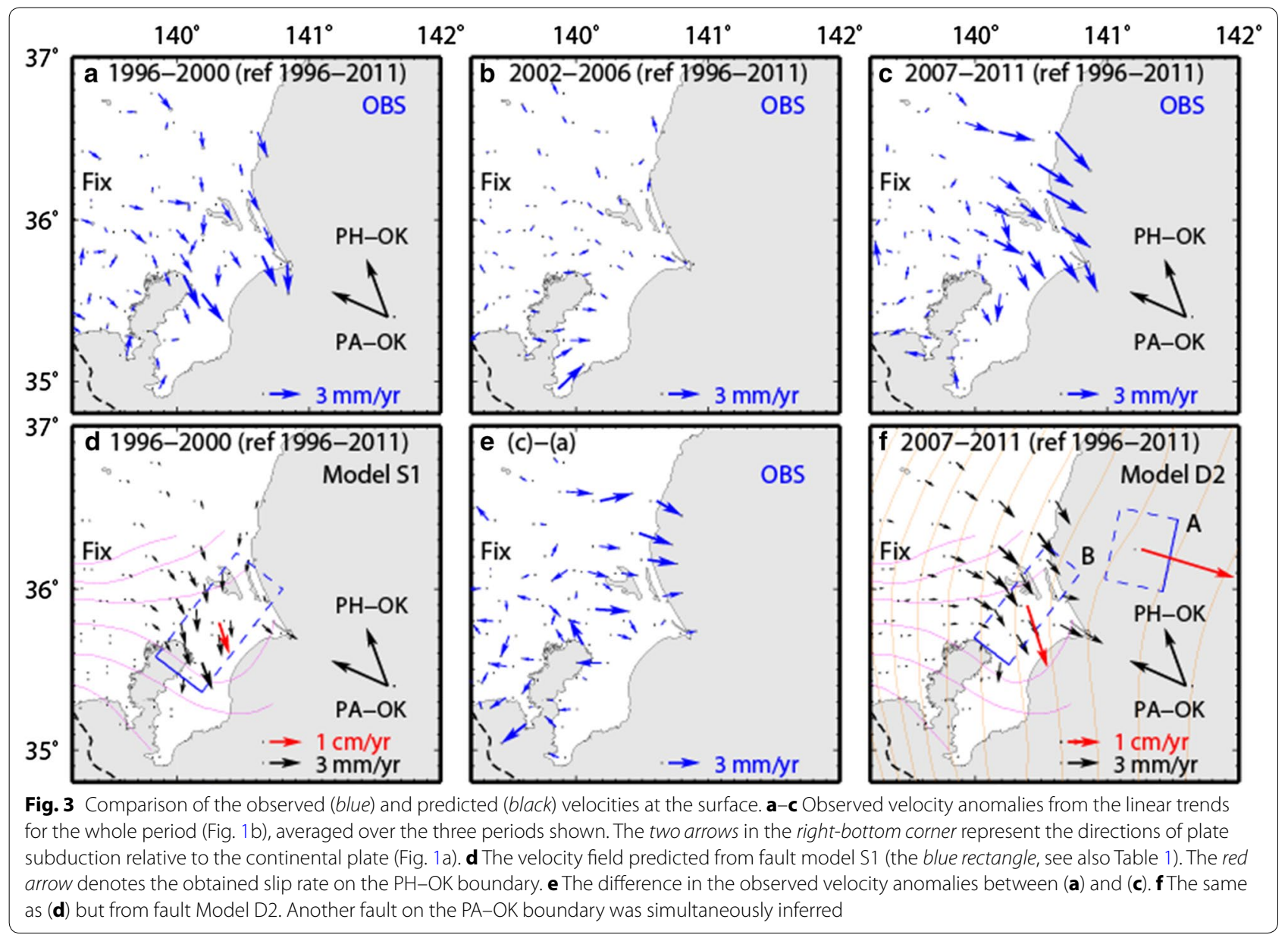


Table 1 Fault models inferred from the GNSS data

\begin{tabular}{lllllll}
\hline Model & Period & Interface $(\mathbf{s})$ & $\boldsymbol{U}(\mathbf{c m} /$ year) & $\boldsymbol{M}_{\mathbf{w}}$ & $\boldsymbol{\sigma}$ (mm/year) & Configuration \\
\hline S1 & I & PHS & 1 & 6.6 & 0.74 & Figure 3d \\
D1 & $96-00$ & PHS/PAC & $1 / 0.5$ & $6.5 / 6.6$ & 0.70 & Additional file 1: Fig. S3a \\
S2 & II & PAC & 2 & 6.8 & 1.04 & Additional file 1: Fig. S3b \\
D2 & $07-11$ & PHS/PAC & $2 / 3$ & $6.6 / 6.7$ & 0.85 & Figure 3f \\
\hline
\end{tabular}

affect the surface displacement rate significantly because the fault was relatively distant from the GNSS stations. Consequently, the fault model inferred for the upper interface of the PHS was almost the same as in Model S1. This double-fault model improved the RMS only slightly (Table 1).

For period II, the directions of the transient displacement rates were close to the opposite of those of the average motion of the PAC (Fig. 3c). Therefore, we first constructed a single-fault model for the upper interface of the PAC (Model S2). The obtained velocity field and parameter sensitivities are presented in Additional file 1: Figures S1 and S2. Table 1 shows that the RMS for the single-fault model exceeded $1 \mathrm{~mm}$ /year. The computed displacement rates were oriented east-southeast, which cannot explain the directions of the observed displacement rates at the stations located near longitude $140.5^{\circ}$ and latitude $35.8^{\circ}$, for example.

Next, we inferred the slip rates on two plate boundaries, simultaneously (Model D2). The variances for different parameters indicated that all the parameters for both faults were well determined (Additional file 1: Fig. S4). Figure 3f shows the velocity field for Model D2. Table 1 shows that the addition of the fault on the PHS significantly improved the RMS $(<1 \mathrm{~mm} /$ year). Interestingly, the location and the magnitude of the fault slip are almost the same as for Model S1 in period I. Due to this additional slip on the PHS, the southward displacement rates were larger in Model D2 than in Model S2 (Additional file 1: Fig. S3). Consequently, Model D2 successfully explained the observed rates in the above-mentioned area.

\section{Discussion}

\section{Comparison with a seismological structure}

Model D2 indicates that a $M_{\mathrm{w}} \sim 6.7$ SSE occurred on the upper interface of the PAC during period II (hereafter, we call the eastern fault on the PAC Fault A). Fault A was located at depths of $30-40 \mathrm{~km}$, similar to the depths where the long-term slip acceleration was dominant (Mavrommatis et al. 2014). Fault A included a region where seismic activities were relatively low in the middle portion (Fig. 4a). The estimated slip rate was $3 \mathrm{~cm} /$ year (Table 1), which was comparable with the average velocity during period II computed from the results of Mavrommatis et al. (2014) (see Additional file 1: supporting text). Considering the coincidence between the depths and the slip rates, the SSE on the PAC inferred in our study is likely the same phenomenon described in Mavrommatis et al. (2014).

Models S1 and D2 also indicate that $M_{\mathrm{w}} \sim 6.6$ SSEs occurred in periods I and II in almost the same area on the upper interface of the PHS (hereafter, we call the western fault on the PHS in Model D2 Fault B). Fault B mostly overlapped a seismic gap at a depth of $\sim 30 \mathrm{~km}$, where low seismic wave velocities were also detected [the area surrounded by the blue curve in Fig. 1b, Sect. 4.2.3 in Nakajima et al. (2009)]. Moreover, a low $V_{\mathrm{p}} / V_{\mathrm{s}}$ ratio, implying the presence of fluids that could cause slow earthquakes, was detected beneath the central part of Fault B (Lake Kasumigaura) at a depth between the lower interface of the PHS and the upper interface of the PAC [Fig. 13f in Nakajima et al. (2009)]. These seismological observations support the occurrences of the two SSEs in this area.

\section{Comparison with background seismicity}

It is known that SSEs increase Coulomb stress on portions of the fault adjacent to the slipping region (e.g., Dragert et al. 2004). The stress change is on the order of $1 \mathrm{kPa}$, which is much smaller than the stress drops of ordinary earthquakes. Therefore, the ability of SSEs to trigger shallower events remains controversial [e.g., Section 4.4 in Katsumata and Sakai (2013)]. In this study, we do not investigate the triggering mechanism further and instead only determine whether the SSEs we identified are temporary correlated with background seismicity.

We estimated the seismicity in the shallower regions adjacent to Faults A and B. Figure 4b shows all the events with $M \geq 2.0$ and focal depths of $20-30 \mathrm{~km}$ listed on the unified Japan Meteorological Agency (JMA) earthquake catalog from 1996-2011. From Regions $A^{\prime}$ and B' (surrounded by the dashed lines in Fig. $4 \mathrm{~b}$ ), we extracted 435 and 115 events, respectively, and applied model-independent stochastic declustering (Marsan and Lengline 2008). In Region $B^{\prime}$, we deliberately excluded the events in the two major clusters located south and east of Fault $B$ to avoid the effects of the SSEs off the Boso Peninsula (Ozawa 2014) and slip on the PAC. 


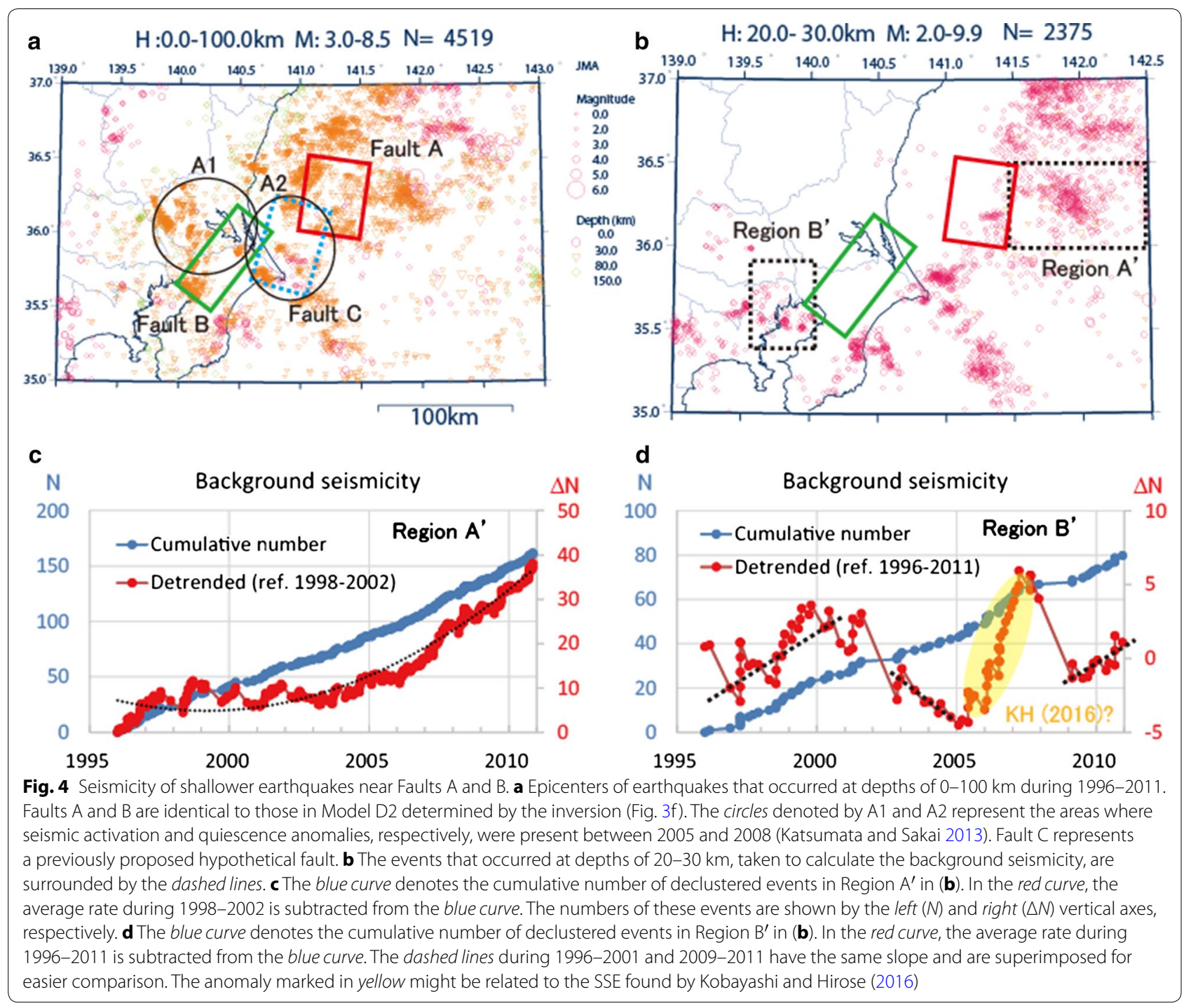

Figure $4 \mathrm{c}, \mathrm{d}$ shows the results obtained for Region $\mathrm{A}^{\prime}$ and $\mathrm{B}^{\prime}$, respectively. In Region $\mathrm{A}^{\prime}$, on the whole, seismicity increased following a second-order polynomial (the broken curve). If we set the reference period to 19982002 , the result is consistent with the acceleration during the late 2000s determined via the GPS observations (Mavrommatis et al. 2014). If we examine the seismicity more closely, the rate during 1996-1999 is slightly higher than that during 1999-2003, which might be due to the smaller slip on the PAC in Model D1, although our inversion result for Model D1 only weakly supported its presence (Table 1). In Region $\mathrm{B}^{\prime}$, we see an abrupt increase in seismicity in 2006. The cause of this increase is unknown and might be related to the episodic uplift reported by Kobayashi and Hirose (2016). Except for this anomaly, the two increases in seismicity during 1996-2001 and
2009-2011 and the decrease in seismicity during 20012005 (dashed lines in Fig. 4d) correspond very well with the slip history on the upper interface of the PHS inferred in our study.

Katsumata and Sakai (2013) found a seismic quiescence for events at depths of $0-50 \mathrm{~km}$ in the area marked by A2 in Fig. 4a during 2005-2008. To explain it, they assumed that an SSE with $M_{\mathrm{w}}=6.5$ occurred on the upper boundary of the PAC (Fault C in Fig. 4a) and showed that the Coulomb stress in the focal area decreased due to the SSE. The surface deformation due to this SSE was too small to be detected by the GNSS (Katsumata and Sakai 2013). Fault C partly overlaps Fault A in the northeast part and the slip period is also common in 2007-2008. Our inversion result indicates that slip on the upper interface of the PAC is dominant at depths 
of $30-40 \mathrm{~km}$. However, we cannot exclude the possibility that a smaller-magnitude SSE also occurred on the down-dip extension of Fault A because of the low degree of detectability by the GNSS. On the other hand, the quiescence in area A2 can be explained even if Fault $C$ was extended northeast along the upper interface of the PAC because the unified fault (i.e., Fault $\mathrm{A}+\mathrm{C}$ ) also decreases Coulomb stress in area A2.

In addition to A2, Katsumata and Sakai (2013) found seismic activation of events at depths of $50-90 \mathrm{~km}$ in the area marked as A1 in Fig. 4a during 2005-2008. Fault C increases the Coulomb stress in the focal area. This area is located down-dip of Fault B. Therefore, slip on Fault B also increases Coulomb stress in area A1 (see Fig. 10 in Dragert et al. 2004 for the spatial pattern of the predicted Coulomb stress change).

Therefore, the presence of the SSEs that we identified in this study is not contradicted by the seismicity anomalies detected by Katsumata and Sakai (2013).

\section{Comparison with external stress changes}

Finally, we compared the obtained slow slip history with external stresses acting on Faults A and B, based on the method presented by Tanaka et al. (2015), to investigate whether external stresses could trigger or drive SSEs. Tanaka et al. (2015) assumed an exponential relationship between the Coulomb stress change $\triangle \mathrm{CFS}$ and the fault slip velocity $V: V=V_{0} \exp \left(\frac{\Delta \text { CFS }}{A}\right)$, where $V_{0}$ and $A$ denote a steady-state velocity under no applied external stress and a constant prescribing slip response to stress, respectively. In this simple model, interactions between the locked zone and the slow slip area are neglected. We computed $\triangle$ CFS for Faults $\mathrm{A}$ and $\mathrm{B}$ due to body and ocean tides and non-tidal variations in the ocean bottom pressure, as described by Tanaka et al. (2015). These stress changes are shown in Additional file 1: Fig. S5a-b and Fig. 5a, b. The frictional coefficient $\mu$ was set to zero, as in Ide et al. (2016). The parameter $A$ is unknown; thus, we assumed it to be $3 \mathrm{kPa}$ based on the observation of tremors in the Nankai Trough (Yabe et al. 2015).

Figure $5 \mathrm{a}$ shows that the $\triangle \mathrm{CFS}$ caused by the nontidal variation on Fault A monotonically increases until 2007 and is almost constant after 2007. The predicted slip velocity anomaly (Fig. 5c) also increases until 2007 if we set the reference period to 1996-2000. We should note that the effect of the longer-period stress change caused by the non-tidal variations is more emphasized in the slip velocity than that of the short-term tidal stress changes with larger amplitudes (Additional file 1: Fig. S5). However, the amplitude of the slip anomaly is only $0.4 \mathrm{~mm}$, which is too small to explain the observed slow slip amount. Moreover, the acceleration after 2007

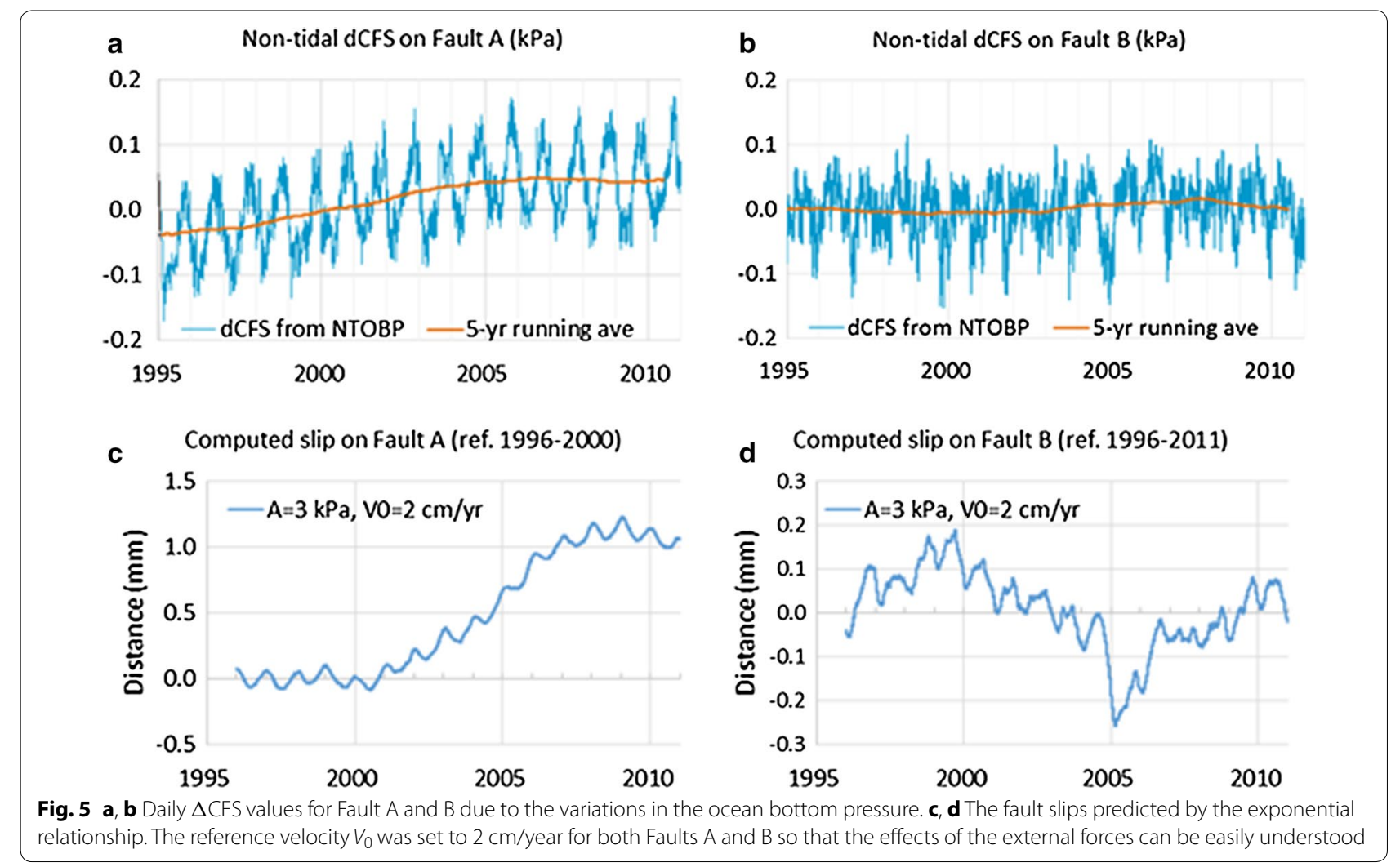


cannot be reproduced by the model. Therefore, we cannot interpret the observed SSE as a direct response to an external stress change. On Fault B, $\triangle \mathrm{CFS}$ changes over an approximately 10 -year period due to the Pacific Decadal Oscillation (Tanaka et al. 2015) (Fig. 5b). Figure 5 d shows that, except for the abrupt increase in 2005-2006, the predicted slip velocity is in excellent agreement with the occurrences of the SSEs. However, the amplitude of the predicted slip anomaly is again too small to reproduce the SSEs themselves.

The above comparison between the observed SSEs and the slip model indicates that, in order to consider whether external stress changes triggered the SSEs, modifications must be made to the model to amplify the slip velocity by two orders of magnitude. However, we cannot simply decrease $A$ in the above exponential relationship. The resultant slips exhibited several extremely large steps exceeding $1 \mathrm{~cm}$ when the ocean bottom pressure changed rapidly, as if coseismic changes occurred. However, this phenomenon does not explain the relatively smooth deformation observed by the GNSS.

\section{Conclusions}

We analyzed the GNSS data for the Kanto district from 1996 to 2011 in conjunction with an inland reference station. The results of the inversion indicated that slip acceleration on the PAC, which was dominant in the Tohoku region (Mavrommatis et al. 2014), also occurred off the Pacific coast of Kanto. The results also suggested that SSEs occurred before the year 2000 and after 2007 at the upper boundary of the PHS at depths of $30-40 \mathrm{~km}$. This fault was located in a region characterized by a seismic gap and low seismic wave velocities. The occurrence periods of the three observed SSEs corresponded well with increasing seismicity near the up-dip extensions at depths of $20-30 \mathrm{~km}$, although it was not clear whether the SSEs triggered these seismic events. To identify the driving force of these SSEs, we assumed an exponential relationship between the shear stress change caused by the external stress changes and the slip velocity. The long-term slip behaviors predicted by the shear stress changes were governed mainly by the non-tidal variations in the ocean bottom pressure, even though their amplitudes were smaller than those of short-term tides. The temporal changes in the slips were in good agreement with the increases in the observed slips, particularly for the SSEs on the upper boundary of the PHS. However, the amplitudes of the predicted slip anomalies were only on the order of $0.1 \mathrm{~mm}$, which were too small to explain the observed slow slips. To confirm whether the external stress changes triggered the SSEs, we must prove quantitatively that such a small fluctuation can evolve into a larger slip event using a more advanced model, such as a rate-and-state friction model that considers a dynamic rupture on a frictionally heterogeneous plate boundary (e.g., Matsuzawa et al. 2010).

\section{Additional file}

Additional file 1. Supplemental information about the GNSS data analysis and the model construction.

\section{Abbreviations}

SSE: slow slip event; GNSS: global navigation satellite system; PAC: Pacific Plate; PHS: Philippine Sea Plate.

\section{Authors' contributions}

YT designed the study, analyzed the data and wrote the paper. SY computed tidal stress changes. Both authors read and approved the final manuscript.

\section{Author details}

${ }^{1}$ Earthquake Research Institute, The University of Tokyo, Yayoi 1-1-1, Bunkyo-ku, Tokyo 113-0032, Japan. ${ }^{2}$ Department of Earth and Planetary Science, The University of Tokyo, 7-3-1 Hongo, Bunkyo-ku, Tokyo 113-0033, Japan.

\section{Acknowledgements}

We thank the Geospatial Information Authority of Japan for the GNSS data. The ocean bottom pressure data were provided by the Meteorological Research Institute of the Japan Meteorological Agency (Usui et al. 2006). Some figures were created using Generic Mapping Tools (Wessel and Smith 1991) and TSEIS (Tsuruoka 1998). This work was supported by JSPS KAKENHI Grant Numbers JP15K17746, JP16H02219 and JP16H06474.

\section{Competing interests}

The authors declare that they have no competing interests.

Received: 1 December 2016 Accepted: 14 March 2017

Published online: 20 March 2017

\section{References}

Dragert H, Wang K, Rogers G (2004) Geodetic and seismic signatures of episodic tremor and slip in the northern Cascadia subduction zone. Earth Planets Space 56:1143-1150. do:10.1186/BF03353333

Hirose I, Kawasaki I, Okada Y, Sagiya T, Tamura Y (2000) A silent earthquake of December 9, 1989, in the Tokyo Bay, as revealed by the continuous observation of crustal movements in the southern Kanto district, central Japan. Zisin 53:11-23 (in Japanese with English abstract)

Hirose F, Nakajima J, Hasegawa A (2008) A three-dimensional velocity structure and configuration of the Philippine Sea slab beneath Kanto district, central Japan, estimated by double-difference tomography. J Seismol Soc Jpn 60:123-138 (in Japanese with English abstract)

Ide S, Beroza GC, Shelly DR, Uchide T (2007) A scaling law for slow earthquakes. Nature 447:76-77

Ide S, Yabe S, Tanaka Y (2016) Earthquake potential revealed by tidal influence on earthquake size-frequency statistics. Nat Geosci 9(11):834-837. doi:10.1038/ngeo2796

Ito A, Sugioka H, Obana K, Hino R, Suetsugu D, Nakahigashi K, Sinohara M, Nakano M, Yamamoto Y (2017) Upper boundaries of the Pacific and Philippine Sea plates near the triple junction off the Boso Peninsula deduced from ocean-bottom seismic observations. Earth Planets Space 69:30-42. doi:10.1186/s40623-017-0608-49

Katsumata K, Sakai S (2013) Seismic quiescence and activation anomalies from 2005 to 2008 beneath the Kanto district, central Honshu, Japan. Earth Planets Space 65:1463-1475. doi:10.5047/eps.2013.06.006

Kobayashi A, Hirose F (2016) Aseismic Slips Synchronized with Earthquakes in Northern Chiba Prefecture, Central Japan. Zisin 69:1-9. doi:10.4294/zisin.69.1

Marsan D, Lengline O (2008) Extending earthquakes' reach through cascading. Science 319:1076-1079. doi:10.1126/science.1148783 
Matsuzawa T, Hirose H, Shibazaki B, Obara K (2010) Modeling short- and longterm slow slip events in the seismic cycles of large subduction earthquakes. J Geophys Res 115:B12301. doi:10.1029/2010JB007566

Mavrommatis A, Segall PP, Johnson KM (2014) A decadal-scale deformation transient prior to the $2011 M_{w} 9.0$ Tohoku-oki earthquake. Geophys Res Lett 41:4486-4494. doi:10.1002/2014GL060139

Nakajima J, Hirose F, Hasegawa A (2009) Seismotectonics beneath the Tokyo metropolitan area, Japan: effect of slab-slab contact and overlap on seismicity. J Geophys Res 114:B08309. doi:10.1029/2008JB006101

Nishimura T (2014) Short-term slow slip events along the Ryukyu Trench, southwestern Japan, observed by continuous GNSS. Prog Earth Planet Sci 1:22-34. doi:10.1186/s40645-014-0022-5

Nishimura T et al (2001) Crustal deformation caused by magma migration in the northern Izu Islands, Japan. Geophys Res Lett 28:3745-3748

Nishimura T, Sagiya T, Stein RS (2007) Crustal block kinematics and seismic potential of the northernmost Philippine Sea Plate and Izu microplate, central Japan, inferred from GPS and leveling data. J Geophys Res 112:B05414. doi:10.1029/2005JB004102

Obara K, Kato A (2016) Connecting slow earthquakes to huge earthquakes. Science 353:253-257. doi:10.1126/science.aaf1512

Okada Y (1992) Internal deformation due to shear and tensile faults in a halfspace. Bull Seismol Soc Am 82:1018-1040

Ozawa S (2014) Shortening of recurrence interval of Boso slow slip events in Japan. Geophys Res Lett 41:2762-2768. doi:10.1002/2014GL060072

Sagiya T et al (2005) Postseismic deformation following the 2004 Mid-Niigata Prefecture Earthquake around the southern part of the source region 2004. Zisin 58:359-369 (in Japanese with English abstract)

Suito H, Ozawa T (2008) Transient crustal deformation in the Tokai district-the Tokai slow slip event and postseismic deformation caused by the 2004 off southeast Kii Peninsula earthquake-. Zisin 61:113-135. doi:10.4294/ zisin.61.113 (in Japanese with English abstract)

Suito H et al (2011) Interplate fault slip along the Japan Trench before the occurrence of the 2011 off the Pacific coast of Tohoku Earthquake as inferred from GPS data. Earth Planets Space 63:615-619. doi:10.5047/ eps.2011.06.053

Tanaka Y, Yabe S, Ide S (2015) An estimate of fluctuating plate subduction velocities caused by tidal modulations and decadal variations in the ocean. Earth Planets Space 67:141-151. doi:10.1186/s40623-015-0311-2

Tsuruoka H (1998) Development of earthquake information retrieval and analysis system on WWW. IPS SIG Technical Report, 1998-115-9, 1998-499, pp 65-70

Uchida N, Matsuzawa T, Nakajima J, Hasegawa A (2010) Subduction of a wedge-shaped Philippine Sea Plate beneath Kanto, central Japan, estimated from converted waves and small repeating earthquakes. J Geophys Res 115:B07309. doi:10.1029/2009JB006962

Usui N, Ishizaki S, Fujii Y, Tsujino H, Yasuda T, Kamachi M (2006) Meteorological Research Institute multivariate ocean variational estimation (MOVE) system: some early results. Adv Space Res 37:806-822. doi:10.1016/j. asr.2005.09.022

Wessel P, Smith WHF (1991) Free software helps map and display data. EOS Trans AGU 72(41):445-446. doi:10.1029/90EO00319

Yabe S, Tanaka Y, Houston H, Ide S (2015) Tidal sensitivity of tectonic tremors in Nankai and Cascadia subduction zones. J Geophys Res Solid Earth 120:7587-7605. doi:10.1002/2015JB012250

\section{Submit your manuscript to a SpringerOpen ${ }^{\odot}$ journal and benefit from:}

- Convenient online submission

- Rigorous peer review

- Immediate publication on acceptance

- Open access: articles freely available online

- High visibility within the field

- Retaining the copyright to your article

Submit your next manuscript at springeropen.com 